\title{
Yearly, Seasonal and Daily Variations of Radio Refractivity
}

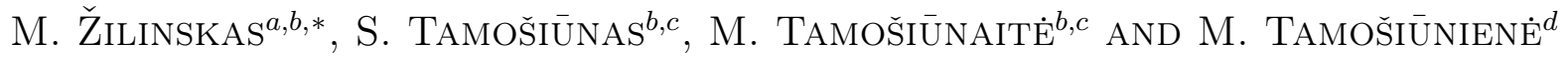 \\ ${ }^{a}$ Department of Radio Communication, Communications Regulatory Authority of the Republic of Lithuania
}

Algirdo 27 A, LT-03219 Vilnius, Lithuania

${ }^{b}$ Faculty of Physics, Vilnius University, Sauletekio al. 9, LT-10222 Vilnius, Lithuania

${ }^{c}$ Institute of Applied Research, Vilnius University, Sauletekio al. 9, LT-10222 Vilnius, Lithuania

${ }^{d}$ Semiconductor Physics Institute, Center for Physical Sciences and Technology

A. Goštauto 11, LT-01108 Vilnius, Lithuania

\begin{abstract}
Yearly, seasonal and daily variations of radio refractivity have been analyzed. The method proposed in the recommendation of International Telecommunication Union ITU has been used. The local meteorological data have been used in calculation of radio refractivity. The highest values of the radio refractivity have been observed in Klaipeda (in Seacoast) in the year 2009. In July, the values of the radio refractivity were highest in all localities investigated here and over all the time of the day in the year 2009. In the continental part of Lithuania (in Vilnius and Kaunas), analysis of radio refractivity has been made by using the meteorological data of longer period (starting from April 2005 up to July 2010). Five-year meteorological data collected in February, April, July and October have been used. It was obtained that the values of refractivity in the year 2010 are much higher than ones obtained in all the years of the period investigated here.
\end{abstract}

PACS: $84.40 .-\mathrm{x}, 41.20 . \mathrm{Jb}$

\section{Introduction}

In design of the radio communication networks, it is important to know the atmospheric radio refractive index (the ratio of the velocity of propagation of a radio wave in free space to the velocity in a specified medium [1]). The knowledge of refractive index is always required when measurements are made in air [2]. The path of a radio ray becomes curved when the radio wave propagates through the Earth atmosphere by reason of the variations in the atmospheric refractivity index along its trajectory $[1,3]$. Refractivity of the atmosphere affects not only the curvature of the radio ray path but gives some insight into the fading phenomenon [1]. The anomalous electromagnetic wave propagation can be a problem for radars because the variation of the refractive index can induce loss of radar coverage [4]. In practice, the propagation conditions are more complicated in comparison with the conditions predictable in design of radio system in most cases.

The meteorological conditions have a significant impact on radio wave propagation through atmosphere. The anomalous propagation is due to the variations of the humidity, temperature and pressure that cause variations in the refractive index [4]. The climatic conditions are very changeable and unstable in Lithuania [5]. The territory of Lithuania belongs to the area where there is

\footnotetext{
* corresponding author; e-mail: mzilinskas@rrt.lt
}

the excess of moisture. The relative humidity is about $70 \%$ in spring and in summer while in winter it is as high as $85-90 \%$ [6]. Lithuanian climate is also characterized by large temperature fluctuations. Difference between the temperature in warmest and coldest months is $21.8^{\circ} \mathrm{C}[5]$.

It was noted in $[7,8]$ that even small changes of temperature, humidity and partial water vapor pressure lead to changes in the atmospheric refractive index. Short time variation of the refractive index over line-of-sight paths of approximately $3 \mathrm{~km}$ in mountainous coastal waters using X-band was presented in [4]. In Ref. [9], the measurements of these meteorological parameters were made in the different time of year and different time of the day. The values of the refractive index have been determined by using measured meteorological data. In Ref. [10], it was mentioned that seasonal variation of refractivity gradient could cause microwave systems unavailability.

Having in mind the variable character of Lithuanian climatic conditions, the influence of the climatic peculiarities on the electromagnetic waves attenuation in the Baltic Sea region has been analyzed in $[11,12]$. The values of the electromagnetic waves attenuation due to rain and clouds have been determined in [11]. In Ref. [12], seasonal and daily variations of radio refractivity have been analyzed in the localities of Lithuania in the year 2009.

In this paper, the data presented in [12] has been extended by the analysis of the yearly, seasonal and daily variations of the atmospheric radio refractivity at the 
ground surface in Vilnius and Kaunas during the longer (2005-2010 years) period.

\section{Calculation of radio refractivity}

The value of the radio refractive index $n$ is very close to the unit and the changes in this value are very small in the time and in the space. With the aim of making them more notable, the term of radio refractivity $N$ is used $[1,13]$ :

$$
N=(n-1) \times 10^{6} \text {. }
$$

According to the Recommendation of ITU [13]:

$$
N=\frac{77.6}{T}\left(p+4810 \frac{e}{T}\right),
$$

where $T(\mathrm{~K})$ is a temperature, $p(\mathrm{hPa})$ is the atmospheric pressure, $e(\mathrm{hPa})$ is partial water vapor pressure. The refractivity is expressed in $\mathrm{N}$ units.

It was mentioned in [1] and [13] that expression (2) may be used for all radio frequencies; for frequencies up to $100 \mathrm{GHz}$, the error is less than $0.5 \%$. There are two terms (the "dry term" and the "wet term") in relationship (2). At the sea level, the average value of $N \approx 315$ [1] is used.

The relationship between the partial water vapor pressure $e$ and the relative humidity $H(\%)$ is [1]:

$$
e=\frac{H e_{\mathrm{s}}}{100},
$$

where

$$
e_{\mathrm{s}}=a \exp \left(\frac{b t}{t+c}\right)
$$

with $t$ temperature $\left({ }^{\circ} \mathrm{C}\right) ; e_{\mathrm{S}}$ is a saturation vapor pressure $(\mathrm{hPa})$ at $t\left({ }^{\circ} \mathrm{C}\right)$ temperature. The values of the coefficients $a, b$ and $c$ (for water and for ice) are presented in [1].

\section{Results and discussion}

The values of the refractivity $N$ have been determined by using (2). The data of temperature, humidity, and atmospheric pressure were taken from http://rp5.ru/ archive.php?wmo_. The partial water vapor pressure $e$ was determined by using Eqs.(3) and (4).

The data presented in our previous paper [12] show that the behaviors of the dependences of refractivity $N$ on the diurnal time are similar in all the localities (Vilnius, Kaunas, and Mažeikiai) situated in the continental part of Lithuania and it is slightly different in seacoast (in Klaipeda). The difference in the climate of continental and sea coastal parts of territory of Lithuania was emphasized in [5] and [11]. The climate of Klaipeda is specified as moderate warm climate. The climate of continental part of Lithuania is typical climate of the middle part of the East Europe. This may explain the difference between the daily variations of $N$ in Klaipéda and in other localities analyzed here.

The highest values of $N$ were in July in all the localities investigated here and over all the time of the day in the year 2009. The lowest values of $N$ were in April in the noontime and in the afternoon until 21th o'clock in all localities investigated here excepting in Klaipeda. In Klaipėda, the diurnal variations of radio refractivity are not marked. The data presented in [12] show that in February 2009 and in October 2009, the diurnal variations of $N$-value are small in all localities.

In Table I, maximum $N$-values and minimum ones, and the difference $\Delta N$ between maximum $N$-values and minimum ones (yearly variation of $N$-value) in the year 2009 are presented. It is seen that the yearly maximum $N$-value $N=350$ was in Klaipeda and minimum one $N=297$ was in Vilnius. The highest value of $\Delta N$ was in Kaunas and the lowest one was in Klaipeda in 2009. In Vilnius and Kaunas, maximum monthly variations of radio refractivity $\Delta N_{\mathrm{m}}$ were observed in April (see Table II). In Mažeikiai and Klaipèda, maximum monthly variations were observed in July.

TABLE I

The maximum yearly $N$-value, the minimum yearly $N$-value, and difference $\Delta N$ between these values in the year 2009 [12].

\begin{tabular}{c|c|c|c}
\hline \hline \multirow{2}{*}{ Locality } & \multicolumn{3}{|c}{ Refractivity, $[N$-units $]$} \\
\cline { 2 - 4 } & $\begin{array}{c}\text { Maximum } \\
N \text {-value }\end{array}$ & $\begin{array}{c}\text { Minimum } \\
N \text {-value }\end{array}$ & $\begin{array}{c}\text { Difference } \\
\Delta N\end{array}$ \\
\hline Vilnius & 338 & 297 & 41 \\
Mažeikiai & 346 & 303 & 43 \\
Kaunas & 344 & 300 & 44 \\
Klaipėda & 350 & 313 & 37
\end{tabular}

TABLE II

The difference $\Delta N_{\mathrm{m}}$ between the maximum and minimum monthly $N_{\mathrm{m}}$-values in the year 2009 [12].

\begin{tabular}{c|c|c|c|c}
\hline \hline \multirow{2}{*}{ Locality } & \multicolumn{4}{|c}{ Difference $\Delta N_{\mathrm{m}},[N$-units $]$} \\
\cline { 2 - 5 } & February & April & July & October \\
\hline Vilnius & 1.98 & 13.07 & 12.58 & 2.90 \\
Mažeikiai & 1.12 & 6.59 & 15.74 & 2.35 \\
Kaunas & 2.31 & 14.99 & 14.38 & 3.38 \\
Klaipėda & 1.24 & 2.33 & 7.91 & 2.17
\end{tabular}

It was concluded in [14] that during the warm season the radio refractivity gradient is more sensitive to moisture gradients than to temperature gradients. The meteorological data collected in the localities investigated here show that the variation of the relative humidity is more noticeable in the warm seasons.

In July, the monthly variation of $\Delta N_{\mathrm{m}}$ in Mažeikiai is twice as much than $N$ variation in Klaipèda. It was concluded in [10] that refractivity gradient variation has noticeable influence in coastal regions of neighboring Latvia during the summer time neither in winter. Such behavior 
of refractivity variation has been observed in the localities investigated here.

According to [10], the theoretical value of $N$ for Latvian territory is $\approx 310 \mathrm{~N}$-units (in February) and $\approx 340 \mathrm{~N}$-units (in August). The following results were obtained by measuring practically in Latvia: $\approx 313 \mathrm{~N}$ -units in February in Riga and Daugavpilis and $\approx 335 \mathrm{~N}$ -units in Riga in August [10]. In Table III, we present the values of the refractivity $N$ at different time of the day averaged over the month in February 2009 in Klaipeda. The average daily $N$-value $N=313$ has been obtained in February 2009 in Klaipeda and the same value was measured in Latvia in [10]. The data presented in [10] show that the $N$-values are the highest in seacoast and they are lower in the continental part of Latvia territory in winter. The results obtained here show that such peculiarity of behavior of $N$-variation has been observed in Lithuanian territory: the highest $N$-values were observed in Klaipeda in all seasons of the year 2009

TABLE III

The refractivity $N$ in Klaipeda in February 2009 [12].

\begin{tabular}{c|c}
\hline \hline Time of day & Refractivity [N-units] \\
\hline 00:00 & 312.97 \\
03:00 & 313.22 \\
06:00 & 312.56 \\
09:00 & 313.50 \\
12:00 & 313.11 \\
$15: 00$ & 312.61 \\
18:00 & 312.74 \\
$21: 00$ & 313.85
\end{tabular}

It was concluded in [12], where the dependences of refractivity $N$ on the diurnal time in four localities of Lithuania have been analyzed, that the behaviors of the dependences of refractivity $N$ on the diurnal time are similar in all the localities (Vilnius, Kaunas, and Mažeikiai) situated in the continental part of Lithuania. In this paper, we selected Vilnius and Kaunas for more detailed analysis. The dependences of average value of $N$ on the time of day in Vilnius and Kaunas in different months of the years 2005-2010 are presented in Fig. 1 and Fig. 2, respectively. In the abscissa axis, the numbers of the months are marked starting from 4 up to 67 as follows: April 2005 is marked as the month number 4, July 2005 is marked as the month number 7, October 2005 is marked as the month number 10, February 2006 is marked as the month number 14, April 2006 is marked as the month number 16 and etc. The last number 67 corresponds to July 2010.

The data presented in Fig. 1 show that the maximum values of radio refractivity $N$ averaged over the month were at 06:00 o'clock and the minimum $N$ values were at 18:00 o'clock during all the years from the period analyzed here.

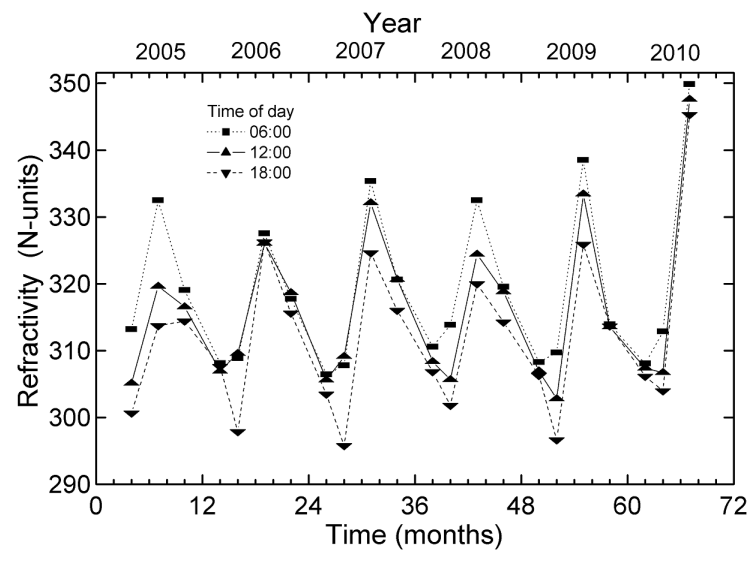

Fig. 1. Dependences of average value of $N$ in the different time of day in Vilnius on the seasons of the years in the years 2005-2010. The years are indicated in the top of the figure.

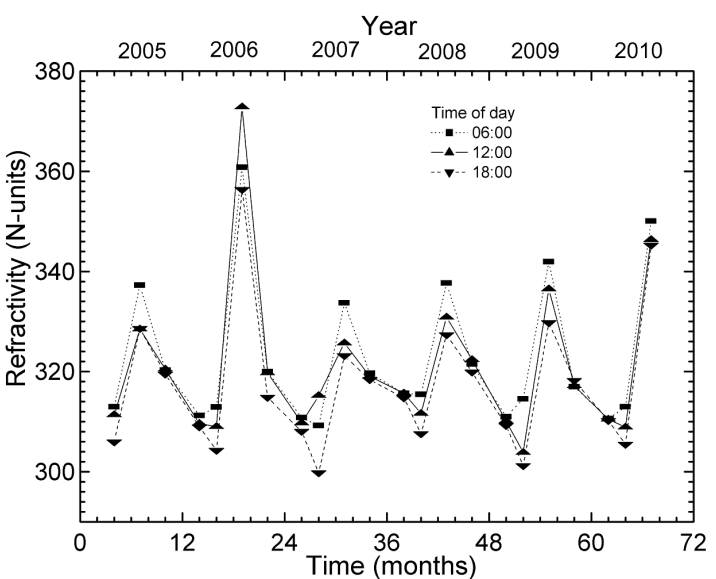

Fig. 2. Dependences of average value of $N$ in the different time of day in Kaunas on the seasons of the years in the years 2005-2010. The years are indicated in the top of the figure.

At 06:00 o'clock, the maximum value $N=350$ was in July 2010 and the minimum $N$ value of 306 was in February 2007. At 12:00 o'clock, the maximum $N=348$ was in July 2010 and the minimum $N=306$ was in February 2007. At 18:00 o'clock, the maximum $N=345$ was in July 2010 and the minimum $N=296$ was in April 2010 .

It is worth to note that $N$ values in the year 2010 are much higher than ones obtained during all the years of the period investigated here in Vilnius. For example, the difference between $N$ values in July 2010 and in July 2006 is $22 \mathrm{~N}$-units at sixth o'clock. However, in Kaunas (see Fig. 2), the maximum value $N=373$ was in July 2006. Maximum diurnal variation of $N$ was $16 \mathrm{~N}$-units in Kaunas. 


\section{Conclusions}

The average daily $N$-value $N=313$ has been obtained in February 2009 in Klaipeda and the same value was measured in sea coast of Latvia in [10]. In February and in October, the daily variations of $N$-value are small in all localities. The yearly maximum $N$-value $N=350$ was in Klaipeda and minimum one $N=297$ was in Vilnius in the year 2009. The highest value of $\Delta N$ was in Kaunas and the lowest one was in Klaipèda. It was estimated that the values of refractivity $N$ were highest in July (in all localities investigated here in 2009) round the clock. Analysis of the meteorological data of longer 2005-2010 years period in Vilnius and Kaunas shows that the values of refractivity are the highest in July 2010 in Vilnius and they are much higher than ones obtained in all the years of the period investigated here during all the time of the day. However, in Kaunas, the highest values of refractivity were determined in July 2006. The maximum $N$ in Kaunas is by $58 \mathrm{~N}$-units higher than the average value of $N \approx 315$ at the sea level at the standard atmospheric conditions.

\section{Acknowledgments}

This work was financed by Communications Regulatory Authority of the Republic of Lithuania under the contract No. (7.2)-IE-44/APS-230000-1171.

\section{References}

[1] R.L. Freeman, Radio System Design for Telecommunications, 3rd ed., Wiley-Interscience, New York 2007.

[2] G. Guo, S. Li, Int. J. Infrared Millimeter Waves 21, $1103(2000)$
[3] B.R. Bean, E.J. Dutton, Radio Meteorology, Dover Publications, New York 1968.

[4] R. Norland, in: Proc. Int. Radar Symp. IRS 2006, Kraków (Poland) 2006, Eds. K. Kulpa, M. Piotrkowski, Institute of Electronic Systems, Warsaw University of Technology, Warsaw 2006, p. 221.

[5] M. Pankauskas, A. Bukantis, Ann. Geograph. 39, 5 (2006) (in Lithuanian).

[6] A. Bagdonas, R. Karalevičienè, The Reference Book of Agrometeorologist, Mokslas, Vilnius 1987 (in Lithuanian).

[7] J.T. Priestley, R.J. Hill, J. Atmosph. Surf. Layer 2, 233 (1985).

[8] N.I. Kablak, Kinematics Phys. Celestial Bodies 23, 84 (2007).

[9] S.E. Falodun, M.O. Ajewole, J. Atmosph. SolarTerrestrial Phys. 68, 236 (2006).

[10] D. Serdega, G. Ivanovs, Electron. Electr. Eng. 6, 39 (2007).

[11] M. Zilinskas, M. Tamosiunaite, S. Tamosiunas, M. Tamosiuniene, PIERS Online 4, 321 (2008).

[12] M. Žilinskas, S. Tamošiūnas, M. Tamošiūnaitè, M. Tamošiūnienè, in: 4th Microwave $\&$ Radar Week: 18th Int. Conf. on Microwaves, Radar, and Wireless Communications MIKON-2010, Vilnius (Lithuania), 2010, Vol. 2, Ed. B. Levitas, Geozondas, Vilnius 2010, p. 423.

[13] The radio refractive index: its formula and refractivity data, Recommmendation ITU- $R$ P.453-9 (1970-1986-1990-1992-1994-1995-1997-1999-2001-2003).

[14] J. Gao, K. Brewster, M. Xue, Adv. Atmosph. Sci. 25, 1098 (2008). 